\title{
artículos
}

\section{La formación del bibliotecario mexicano a través del bachillerato y la opción técnica en biblioteconomía}

\author{
"José Alfredo Verdugo Sánchez \\ Carlos Compton García Fuentes \\ Juan José Calva González
}

\section{RESUMEN}

El do cu men to se com po ne bá si ca men te de cin co par tes. En la pri me ra de ellas se es tu dian los an tece den tes y carac te rís ticas principales de la educación me dia su pe rior, ni vel en el cual se en cuen tra in ser ta da la opción técnica mo ti vo de es tu dio. La se gun da par te ana li za las pro pues tas delCo le gio Na cio nal de Bi blio te ca rios so bre la op ción téc ni ca en bi blio te co no mía, las cua les, de algu na ma ne ra, sirven como mo de lo para el di seño de nue vos pro gra mas y la res truc tu ra ción de otros. La par te tres des cri be y ana liza los con cep tos más im por tan tes de los di fe ren tes pla nes de es tu dio del ba chille ra to téc ni co que exis ten ac tual men te en nues tro país, así como el anteproyectopropuesto para el estado de Tabasco,destacándose, asimis mo, las se me jan zas y diferen cias en tre cada uno de ellos. La cuar ta par te pre sen ta un pa no ra ma ge ne ral del mer ca do de tra bajo y las pers pec ti vas la bo ra les de los egre sados de la op ción téc ni ca en bi blio te co no mía. In clu ye el es tu dio y los re sul ta dos de una en cues ta rea li za da a los em plea dos de centros bibliotecarios, considerados grandes captadores de personal bibliotecario. Finalmente, la parte quinta está dedicada a las observaciones, con clu siones y recomen da ciones ge ne rales en las cuales se ob serva cla ra men te la ne ce si dad de re es truc tu rar cuidadosamente los planes y programas de estudio de esta opción técnica.

\begin{abstract}
This do cu ment con sists essen tia lly of five parts. In the first part, the an te ce dents and prin ci pal cha rac te ris tics of high school educa tion are stu died. The te chni cal op tion of li brary scien ce is lo ca ted at this le vel of e du ca tion. The se cond part analyzes the pro posals of the National College of Librarians (Colegio Nacional de Bibliotecarios) concerning the technical option in library science. These proposals serve, in some ways, as models for the design of new programs as well as the restructuring of others. The third part des cri bes and analyzes the most im por tant con cepts of the va rious plans of study that cu rrently exist in the te chni cal high schools of our coun try, as well as a pro ject pro po sed for the sta te of Ta bas co, no ting the similarities and diffe rences bet ween each one of them. The fourth part pre sents a ge ne ral over view of the job mar ket and fu tu re e mployment pers pectivesforgraduates of the technical option in li brary scien ce. It in clu des the study and analysis of a survey taken of the em plo yees of the li brary centers that are con si de red the lar gest em plo yers of li brary per son nel. Fi nally, the fifth part contains general observations, conclu sions, and re com men da tions, in which is clearly seen the need to res truc tu re ca re fully the plans and pro grams of study of this technical option.
\end{abstract}

\section{INTRODUCCION}

Para el año de 1980 en nues tro país, exis tía un dé fi cit de más de seis mil bibliotecarios en las diversas bibliotecas y otras unidades de información del país'.

Creemos que en 1989 este dé fi cit, le jos de dis mi nuir, ha aumentado debido a la implementación del Programa Nacio- nal de Bibliotecas Públicas de la Secretaría de Educación Pública.

Es así que el sistema educativo nacional, en un intento de ofre cer ca pa ci ta ción para el tra ba jo a los egre sa dos del ba chillerato, ha ofrecido una opción técnica en biblioteconomía. Sin em bar go, el es ca so nú me ro de egre sa dos de esta op ción y su aun más pe que ño nú me ro de egre sa dos que tra bajan en bibliotecas, nos hace du dar de la efi cien cia de esta op ción y del

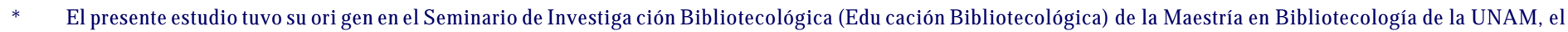
cual fue coordinado por la Maestra Estela Morales Campos.

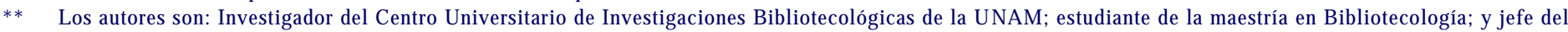
Departamento de Planeación de la Dirección General de Bibliotecas de la UNAM, respectivamente. 
interés del Es ta do en es ta ble cer una ade cua da for ma ción técnica para el personal bibliotecario.

\section{Objetivos}

Los objetivos para realizar el presente estudio, fueron:

a) Conocer si las opciones técnicas en biblioteconomía ofreci das en elDis tri to Fe de ral cum plen con sus obje ti vos ins ti tucionales.

b) Es table cer siel tipo de ca pa ci tación ofre ci daes la ade cua da a las necesidades laborales del mercado.

c) Establecer si el diseño curricular de estas opciones es el adecuado a los objetivos institucionales de capacitación.

d) Es ta ble cer la in fluen cia que el Co le gio Na cio nal de Bibliote carios, comoórga no rec tor de labibliote co logía en México, ha tenido en el diseño curricular de estas opciones.

Con la elaboración del presente trabajo se pretende hacer algu nas reflexiones so bre la op ción téc nicaen bibliote co no mía: sus antecedentes, desarrollo y perspectivas.

\section{Hipótesis}

Al formularse la realización de este trabajo se plantearon las hipótesis siguientes:

a) La opción técnica en biblioteconomía es innecesaria en el bachillerato.

b) La ca pa ci ta ción ofre ci da esta di sa so cia da de la rea li dad laboral en cuanto a oferta de trabajo.

\section{Metodología}

La me to do logía pro pues ta para la rea lización del trabajoconsistió en:

a) Recopilación de los documentos generales sobre educación me dia su pe rior téc ni ca en Mé xi co y en es pe cial de la opción en biblioteconomía.

b) Análisis comparativo de los documentos básicos sobre el tema, como son: la IV Mesa Redonda, las ActividadesProfesionales y no Profesionales del CNB, así como los planes de estudio de las diferentesescuelas que imparten la op ción técnica en bibliotecología.

c) Diseño, aplicación e interpretación de resultados de un cuestionario encaminado a recabar información so bre los estu dian tes y egre sa dos de la op ción téc nicaen biblio te conomía y su captación en el mercado de trabajo.

\section{ANTECEDENTES}

Para comprender el bachillerato técnico en biblioteconomía, es necesario señalar que el Sistema Educativo Nacional está compuesto por varios niveles, y en uno de ellos (nivelmedio superior) se inscribe el bachillerato técnico, caso de nuestro estudio.

De ma ne ra es que má ti ca se pre sen ta rán cada uno de los ni veles, haciendo énfasis en las características técnicas y propedéuticas del nivel medio superior. Asimismo, se hará una semblanza de las escuelas que tradicionalmente han impartido esta opción técnica.

\section{Educación Media Superior}

En el país, el sistema edu ca ti vo está es truc tu ra do de la for ma siguiente:

Niveles:

Educación elemental.- Comprende:

a) La enseñanza preescolar

b) La enseñanza primaria

Educación media.- Abarca:

a) El ciclo básico o secundaria

b) El ciclo superior o bachillerato (este último es el comúnmente conocido como educación media superior).

Educación superior.- Es aquella que comprende:

a) La enseñanza universitaria

b) La enseñanza tecnológica

Los estudios de bachillerato son ofrecidos en la mayoría de los ca sos por las pro pias uni ver si da des e ins ti tu cio nes edu cativas superiores. La población escolar de bachillerato era de 230676 alumnos en 1970; creció a 652580 en 1977, y a casi un millónen 1981.Estosin cre mentosrepercuten directamente en el in gre so al ni vel su pe rior ${ }^{3}$. Más re cien te men te, en el ciclo escolar 1986-87, la matrícula total en el bachillerato fue de 1627384 en 3658 escuelas ${ }^{4}$. En el caso del Distrito Federal, debido a la insuficiente capacidad de la UNAM y el IPN para atender la creciente demanda de educación media superior, fue creado el Colegio de Bachilleres, como organismo público descentralizado, encargado de proporcionar educación media superior y capacitación técnica.

\section{Diferencias entre la Secundaria y el Bachillerato}

Lasdiferencias en cuan to alafinalidad, naturale zainstitucional, planes de estudio y la procedencia del personal entre la secundaria y el bachillerato, de acuerdo a Espinosa Suñer son:

a) Finalidad.- La educación secundaria pretende continuar a partir de la pri maria, la for ma ción del edu can do, coad yu vando a que participe en su pro piafor ma ción, y pro por cio nán do- 
le ala vez las ba ses de cono ci mien to in dis pen sables paraelingreso a un nivel posterior; por otra parte, el fin del bachillerato es el aportar al educando los conocimientos necesarios para incorporarse a la educación superior, y prepararlo para una eventual incorporación a la vida económicamente activa.

b) Naturaleza institucional.- Los planteles de enseñanza secun da ria son organi za dos en tor no a una di rec ción aca démica y ad mi nis tra ti vacen tral, de pen dien te de la Se cre ta ría deEducación Pública (SEP), en la mayoría de los casos, y en otros dependen de una institución de educación superior; en cambio, los plante les del ba chille ra to, en su gran ma yo ría, de penden académicamente o forman parte de una institución de educación superior, y en una mínima parte, dependen de la SEP.

c) Pla nes de es tu dio.- En la se cun da ria, el plan de es tu dio está su je to a cier ta ri gi dez de tres o cua tro mo de los fi jos es ta ble cidoscentralmente; en con traparte, en el bachille ratolos planes de es tu dio de pen den de las de ci sio nes adop ta das por el or gat nis mo, la ins ti tu ción o las au to ri da des de que cada tipo de bachilleratodepende, existiendo en el país por estas razones alrededor de 120 planes de estudio diferentes en contenido y duración.

d) Formación y procedencia del personal docente.- En la secundaria, el personal docente es egresado en su inmensa mayo ría de una ins ti tu ción pe da gó gi ca, mien tras que en el ba chillerato éste es egresado en su mayoría de una institución que imparte la enseñanza superior sin enfoque pedagógico.

En re su men, po dría mos afir mar que la edu ca ción me dia su perior tiene como características principales, las siguientes:

- Su finali dad es la edu ca ción pro pe déu ti ca para la en señan za superior, así como una opcional preparación para el trabajo.

- Sus planteles, por lo general, dependen o forman parte de una institución de educación superior.

- Los planes de estudio varían según cada institución.

- El personal docen te provie ne de una ins ti tu ción su pe rior no pedagógica.

\section{Educación Media Superior Técnica}

La educación media superior técnica comprende:

a) El bachillerato tecnológico.

b) La educación profesional técnica.

Ambasmodalidades soncoordinadas porelSistemaNacional de Edu ca ción Tec no ló gi ca, el cual de pen de de la Sub se cre tar ría deEdu ca ción e In ves ti ga ción Tec no ló gi ca de la Se cre ta ría deEdu ca ción Pública. El Sis te ma ope ra en los Ni ve les me dio superior, superior y posgrado.
El bachillerato tecnológico(bivalente) es propedéuticoy termi nal al mis mo tiem po, pues pre pa ra al es tu dian te para con tinuar estudios superiores o para incorporarse al trabajo productivo merced de una preparación técnica que tiene una duración de seis semestres.

La educación profesionaltécnica en sus acepciones de técnico profe sional, téc nicoter minaly profe sional téc nico, preparapara un trabajoin ter me dio en tre el delobre rocalifica do yel del profesional. Los estudios duran ocho semestres (un promedio de seis en los Centros de Estudios Tecnológicos). Estos estudios no equivalen al bachillerato.

Para ob te ner el títu lo y cé du la profe sio nal téc nica, se re quie re un ser vi cio so cial, y el tra bajo de te sis con su ré pli ca. El tí tu lo de técnico profesional se otorga en los Centros de Estudios Tecnológicos Industriales y de Servicios (CETIS) y en los Cen tros de Es tu dios Cien tíficos y Tec no ló gi cos (CECYT); el de profesional técnico en el Colegio Nacional de Educación Profe sional Técnica(CONALEP), y el de técnico terminales otor ga do en aque llas es cue las que dan una pre pa ra ción téc nica de seis semestres.

Paracursarelbachille ratobivalen te exis tenlas siguientesinstituciones:

- Los Centros de Estudios Científicos y Tecnológicos, depen dien tes del IPN, que en nú me ro de quin ce, se lo ca li zan en el D.F.

— Los Centros de Bachillerato Tecnológico, en las áreas:

- Agropecuaria (CBTA)

- Industrial y de servicios (CBTIS)

- Ciencias del mar (CET-MAR)

- Cen tros de Es tu dios Tec no ló gi cos In dus tria les y de Ser vicios (CETIS)

—Enelinterior de la República, al gu nosins ti tu tos tec no lógi cos y el Centro de Enseñanza Técnica Industrial.

Para cursar la educación profesional técnica existen las siguientes instituciones:

— Los Centros de Estudios Tecnológicos (CET)

- Los Centros de Estudios Tecnológicos Industriales y de Servicios (CETIS)

Las anteriores instituciones también proporcionan preparación técnica en los estados de la República.

\section{Bachillerato Bivalente con opción Técnica en Biblioteco- nomía}

Esta op ción téc ni ca es ofre ci da en la Es cue la Na cio nal de Bi- 
blioteconomía y Archivonomía (ENBA), dependiente de la SEP; en el Colegio de Ciencias y Humanidades (CCH), depen dien te de la UNAM; y en el Co le gio de Ba chi lle res, or ganismo público descentralizado.

Escuela Nacional de Biblioteconomía y Archivonomía.- Fue fundada en $1945^{7}$ teniendo entre sus objetivos principales la for ma ción profe sional, lafor mación téc nicay lacapa ci tación del personal bibliotecario dependiente de la Secretaría de Educación Pública. En 1975 estableció formalmente el Bachille ra to Téc ni co en Biblio te co no mía, el cual cons ta de nueve materias técnicas en la opción y está orientado a las ciencias sociales y administrativas. ${ }^{8}$

Es la institución más antigua con un bachillerato técnico en biblio te co no mía, y tie ne como obje ti vo ge ne ral el pro porcionar al alumno "los conocimientos y habilidades necesarios que le permitantrabajar en los diferentes tipos de bibliotecas y centros de documentación del país".

Cole giode CienciasyHumanidades.- El 26 de ene ro de 1971 el Con se jo Uni ver si ta rio de la UNAM apro bó la crea ción del Colegio y de la Unidad Aca démica delCic lo de Bachillerato, creándose el 27 de julio de 1976 la Dirección General de la Unidad Aca démicade los Ciclos Profe sionaly de Pos grado.

Su establecimiento en el nivel medio superior obedecía a la necesidad de contar con una mayor capacidad en el bachillerato de la UNAM, así como de formar técnicos de nivel medio, y el de alcanzarniveles de educación cada vez más altos. El CCH se creó como un instrumento innovador que permitiera efectuar cambios en la UNAM, sin alterar su estructura académica establecida. En lo que se refiere a la preparación técnica en el nivel medio superior, son propósitos instituciona les el crear un tipo de edu ca ción ca paz de ge ne rar los re cursos humanos que sean útiles al país, a través de la enseñanza técnica.

El Colegio en el ciclo de bachillerato tiene cinco planteles: Azcapotzalco, Naucalpan, Oriente, Sur y Vallejo, con once opciones técnicas que se ofrecen a partir del tercer semestre. Bibliote cologíaes ofrecidaen loscincoplanteles, ${ }^{10}$ iniciándose esta op ción en 1977. El di se ño cu rri cu lar, en ge ne ral, guardaba una amplia similitud con los programas existentes en la épo ca, como son: el de la ENBA, el de la Uni ver si dad de Guadalajara y el curso intensivo ENBA-CONACyT.'

Cole giodeBachilleres.- Fue fun da do en 1973 como or ga nismopúblicodescentralizado del Estado, contando actualmente con veinte plan te les en el área me tro po li ta na, más otros en pro vin cia. En 1980 se es table cióla op ción téc ni caen biblio teconomía, la cual es ofrecida en dos planteles. En esta institución es obligatorio acreditar una de las diez opciones que se ofrecen. Es importante hacer no tar que esta op ción cuen ta en su plan de estudios con ocho materias técnicas, y el resto lo constituyen materias del bachillerato general. ${ }^{12}$

\section{PROPUESTAS DEL COLEGIO NACIONAL DE BI- BLIOTECARIOS SOBRE LA OPCION TECNICA EN BIBLIOTECONOMIA}

\section{Antecedentes}

ElCole gio Nacio nal de Biblio te carios como Aso cia ción Ci vil que agru pa al gre mio pro fe sio nal de la Bi blio te co lo gía me xicana, ha es tableci do en tre sus obje ti vos el re gu lary vi gi lar las actividades bibliotecarias del país. Esto implica, entre otras co sas, "la for ma ción de re cur sos hu ma nos de la más alta ca lidad".

Bajo este precepto, el Colegio ha realizado tres mesas redondas con los profesionales comprometidos en el proceso educati vo y for ma ti vo del biblio te cario. LaSe gun da Mesa ${ }^{14}$ rea liza da en 1981 pro po ne el nú cleo bá si co para la li cen cia tu ra; la terceraefec tua daen $1982^{15}$ corres pon de a los criterios nor mativos para la maestría y la cuarta, ${ }^{16}$ efectuada dos años después, se con cre ta a se ña lar los li nea mien tos del nú cleo bá si co para la opción técnica.

En el mismo año que se efectuó la Segunda Mesa (1981) el Cole gio emi tió un do cu men to que per mi te vi sua li zar con mayorprecisiónlasactividades profesionales ${ }^{17}$ y las no pro fe sionales, realizadas en la biblioteca.

Dicho documento permite abordar con una base teórica las posibilidades que las escuelas de bibliotecología tendrían en el plan tea mien to de sus car tas cu rri cu la res en los dis tin tos nive les de la edu ca ción bi blio te co ló gi ca, es de cir, op ción téc nica, licenciatura y maestría.

\section{Mesa Redonda}

El enun cia do ge ne ral de ésta se ña la que el téc ni co en bi blio teconomía, funcionará como auxiliar en el de sa rro llo de las la bores desempeñadas, dirigidas y vigila das porelprofesional.

Por tanto, se es pe ra que la for ma ción de este au xi liar- téc ni co estélo su ficien te men te di ri gi da al cumplimien to de tal co metido.

Al analizar el objetivo del plan para la opción técnica se advierte que los egresados deberán ser capaces de realizar, por lo menos, seis actividades específicasy una genérica sin precisión, que son:

a) Ad qui riry re gis trar los di fe ren tes ti pos de ma te ria les do cumentales, previamente seleccionados por el profesional.

b) Realizar labores de catalogación descriptiva, para efectos de descripción física de los materiales documentales.

c) Manejar colecciones bibliográficas y ordenar catálogos.

d) Proporcionar los servicios de circulación y reprografía. 
e) Transcribir y ordenar físicamente fichas para la elaboración de bibliografías y ofrecer consulta básica.

f) Re gis trary tabular los da tos es ta dís ti cos de las bibliote cas.

g) Auxi liar, en ge ne ral, en el de sa rro llo de las la bo res a que se re fie re el ob je ti vo y las fun cio nes de la li cen cia tu ra en bi bliotecología.

Sin em bar go, el plan de es tu dio re fle ja, sin lu gar a du das, que el bachiller técnico en biblioteconomía debería ser capaz (o casi ca paz), de rea li zar las ac ti vi da des re ser va das para el profe sional. No de be mos ol vi dar, que la fun ción prin ci pal del bachillerato es preparar al individuo en el aspecto más general del conocimiento para un ingreso futuro a un nivel profesional.

Si nos ubicamos en el bachillerato técnico en biblioteconomía, según este documento, sabremos que el requisito inmediato después de la secundaria es haber cursado los primeros cuatro se mes tres del pro gra ma de ba chi lle ra to y "si se con side ra que en este ni vel los par ti ci pan tes en el proce so ob tie nen la oportunidad de orientar tempranamente su vocación, la oportunidad de su incorporación al trabajo, y una formación sóli da para rea lizar las ac ti vi da des de apoyoen las bi blio te cas con base a conocimientos y experiencias elementales", ${ }^{19}$ nos da mos cuen ta de que la orien ta ción delCNB dis ta bas tan te de la rea li dad, a pe sar de los im por tan tes es fuer zos al "so me ter a un análi sis más in te gral los pla nes y pro gra mas del téc ni co en bibliotecología", ${ }^{20}$ ya que los contenidos mínimos de los distintos programas ubican al estudiante en un nivel superior al bachillerato.

Aunque para el núcleo del progra ma de es tu dio del ni vel técnico, se señalan las mismas áreas del plan de la licenciatura, éste debe representar sólo el $25 \%$ del plan general ya que el restante $75 \%$ deberán constituirlo las asignaturas propias del bachillerato.

Area general 10\%

Administración 10\%

Organización bibliográfica $40 \%$

Servicios e información $40 \%$

En los casos del bachilleratoen cien cias so cia les, la par te adminis tra ti va se in clu ye en el $75 \%$ que co rres pon de a las ma terias propias del bachillerato, en cuyo caso la distribución del núcleo básico varía:

Area general 10\%

Organización bibliográfica $45 \%$

Servicios e información $45 \%$

Con res pec to al $10 \%$ seña la do para el área ge ne ral en este úl ti- mo caso, consideramos que las materias ubicadas en este rubro deberán ser relacionadas con la bibliotecología, pese a que el documento de la IV Mesa Redonda no lo manifiesta; sin embargo en el documento de la II Mesa Redonda sobre For mación de Re cursos Hu manos para las Biblio te cas, ${ }^{21}$ celebra daen 1981, síes pe ci fi ca que este por cen taje co rres pon de a asignaturas generales de bibliotecología, siendo éstas:

- Introducción a la bibliotecología

- Historia del libro y de las bibliotecas

Técnicas de investigación

Determinado el núcleo básico, se establece de igual forma tanto el perfil profesiográfico del técnico y los contenidos programáticos de cada una de las asignaturas. Estos dos elementos hacen reflexionar a conciencia sobre la importancia, alcances y limitaciones delbachilleratotéc nicoenbiblioteconomía:

1o. Habría que ubicar con mayor precisión que un auxiliar téc ni co ren di ría ma yo res fru tos si se le ca pa ci ta para una ac tividad determinada den tro de la bi blio te ca, bien sea: re gis trar publicaciones periódicas, intercalación, consulta elemental, catalogación, etc. y no pretender formarlo en todas las áreas de la bibliotecología, puesto que ya existen los programas de la licenciatura, los cuales tienen una mayor cobertura.

2o. Que dadas las características de formación académica, madurez, edad, etc. del estudiante del bachillerato, es difícil que éste muestre el interés por desarrollarse "profesionalmen te" cuan do el obje ti vo del ba chille ra to es as pirar a unacarrera profesional y en el caso del bivalente es preparar, además, para el trabajo a nivel técnico.

3o. Es im por tan te la dis trac ción de re cur sos hu ma nos, eco nómicos, materiales, etc. y sobre todo, de tiempo, que tanto las es cue las como los es tu dian tes ha cen al pro por cio nar y cur sar un número bastante considerable de asignaturas (nueve) dispares en el plan general del bachillerato, que ade másten drán que acreditarse.

4o. A pe sar de los gran des es fuer zos rea li za dos por el Cole gio Nacional de Biblio te ca rios al es tu diar la op ción téc ni cacomo posibilidad de resolver el problema de falta de recursos humanos capaci ta dos para nues tras bi blio te cas, esto no ha dado los resultados esperados. Consideramos que una causa impor tan te es el ele va do ni vel de la cu rrícu la en el nú cleo bá si co y lo que se es pe ra del egre sa do a tra vés del obje ti vo se ña la do. Un ejem plo cla ro es el he cho de que el ba chi ller es tu die la biblio gra fía an te rior a 1450, la del si glo XVI has ta el si glo XX, la his to ria del li bro y las bi blio te cas, etc., sien do que su ac ti vidad se concretará al sellado, marcado, cotejo de facturas, préstamo de mostrador, etc. Es decir, existe una descompensa ción en tre lo que se es tu dia (con te ni dos pro gra máticos) y lo que real mente se hace en labiblio te ca (ac tividades) en caso de poder ser contratado en alguna de ellas. 
De este aspecto es im por tan te des ta car que los pro gra mas recomendados en esta IV Mesa incluyen contenidos marcados para algunas asignaturas de la licenciatura y por ende la bibliografía recomendada es parte de la que se estudia también en este nivel superior.

Por otro lado, es significativoque enlabibliografíaseñalada, como es el caso de la asig na tu ra "ex ten sión bi blio te ca ria", un alto porcentaje se marca en idioma extranjero (inglés, francés), lo cual indica que la gran mayoría de los estudiantes no ten drán ac ce so a ella. En este mis mo caso, cabe se ña lar que de acuerdo a los objetivos marcados para la asignatura y el programa, ${ }^{22}$ el alumno egresado de esta opción técnica no podrá uti li zar los re cur sos de la ma te ria ni asi mi lar los da das sus ca rac terís ticas. Se pre sen ta como una asig na tu ra de un ni vel que no corresponde a un estudiante de bachillerato.

De acuer do a como se pre sen ta el plan cu rri cu lar de la op ción técnica del documento citado, observamos que éste corresponde a un nivel superior al del bachillerato, si tomamos como pa rá me tro los con te ni dos míni mos se ña la dos para la licenciatura. Si bien habrá que reconsiderar esta alternativa, también ha bría que ha cer lo con el plan de es tu dio de la li cenciatura y quizá con el de la maestría.

Desde este cuadro general podríamos inferir que la currícula de los diferentes bachilleratos técnicos en biblioteconomía (en su nú cleo bá si co) es muy ele va do, o bien, que la li cen ciatura existente queda en un nivel inferior.

\section{Actividades profesionales y no profesionales}

El do cu men to emi ti do por elCNB hace una se rie de re co mendaciones con respecto al desempeño de las actividades de la biblio te ca. Dis tin gue en tre lo que debe ha cer un profe sionaly lo que debe ha cer un no pro fe sio nal a tra vés del se ña la mien to de las distintas actividades.

Se consideraqueeldocumento ${ }^{23}$ es de gran valor en la determinación de los contenidos mínimos (sobre todo para el bachi lle ra to téc ni co) ya que éste es con si de ra do den tro de la biblioteca como personal no profesional.

En los grandes grupos de actividades que se encabezan en el citado documento, destacan:

\section{a) Administración}

b) Dirección de personal

c) Capacitación de personal

d) Relaciones públicas

e) Selección de material bibliográfico

f) Adquisición de material g) Catalogación y clasificación

h) Preparación física del material

i) Servicio de préstamo*

j) Servicio de consulta

k) Control de estantes y ficheros

Esto refleja que las once actividades forman el "catálogo"de grandes rubros de lo que podría hacerse en una biblioteca en términos generales.

Ahora bien, si se ha detectado este listado y sólo siete de las actividades contem plan tareas no profe sionales, es ló gicosupo ner que la for ma ción re que ri da para un ba chi ller téc ni co en biblioteconomía, que laborará como auxiliar del profesional de la biblioteca, tendrá que ser precisamenteen estos rubros, sin des viar su aten ción en otra en se ñan za que no le será de utilidad práctica al vender su fuerza de trabajo.

En este caso, la materia "Introducción a la Bibliotecología", de acuerdo al programa que se presenta, no tendría razón de ser, dado que con el conocimiento con ella adquirido, el bachiller no ten drá ac ti vi dad que rea li zar. La mis ma si tua ción se presenta, por ejemplo con las asignaturas "Introducción a la Bibliografía" y "Extensión bibliotecaria".

Consecuentemente con lo expresado en el documento que citalas ac ti vida des profe sionales y las no profe siona les, la IV Mesa Redonda deja ver un notorio desajuste en la propuesta de con te ni dos míni mos para el nú cleo bá si co de la op ción técnica con respecto a las funciones que el personal no profesional va a desempeñar en la biblioteca.

Ten dría que ana li zar se la ra zón (si es que exis tie ra) por la cual en am bos do cu men tos sien do del pro pio Co le gio Na cio nal de Bibliotecarios existe tal discrepancia.

Vale la pena in sis tir en que de acuer do a las ac ti vi da des con side ra das por el CNB como no pro fe sio na les, los pro gra mas de las asignaturas tendrían que variar notablemente si lo que se pre ten de con el bachille ra to con op ción téc ni caen biblio tecono mía es lacapaci tación para el trabajo y de ele men tos for mados en alguna actividad de la biblioteca.

Consideramos con esto la prudencia de ver la posibilidad de for mar téc ni cos, (si asíse les quie re lla mar) "es pe cia li za dos" en una sola actividad a realizar, y no "bachilleres técnicos" que no sean es pe cializa dosen nin gu na ac ti vi dad con cre ta. La dispersión de los conocimientos señalados en los programas de las ma te rias su ge ri das por el CNB son el re fle jo de este bachiller técnico. 


\section{LOS PLANES DE ESTUDIO DEL BACHILLERATO TECNICO Y SUS REPERCUSIONES}

De acuerdo a los datos recabados podremos señalar que actualmente sólo existen tres instituciones encargadas de impartirelbachillera to téc nicoen biblioteconomía obibliotecología y que cada una de ellas cuenta con su propio plan de estudios, pudiendo indicar que existen marcadas semejanzas entre ellos, a pesar de pertenecer a diferentes instituciones; además podríamos señalar las semejanzas con lo propuesto por el CNB. Tam bién se con si de ra para este caso el An te proyecto Tabasco.

\section{Escuela Nacional de Biblioteconomía y Archivonomía}

Dado que esta es cue la es la pri me ra ins ti tu ción que ofre ce un ba chille ra to con una op ción téc ni ca en bi blio te cono mía, es de notar se su in fluen cia en las pos te rio res es cue las que han ofrecido esta opción.

Puesto que el objetivo general de la opción téc ni ca en bi bliote co no mía de esta es cue la ya se ha men cio na do en los an te ceden tes de este tra bajo, de ma ne ra com ple men ta ria se men cionará el perfil profesiográfico de dicha opción:

- Auxiliar en las labores profesionales de la biblioteconomía.

- Aplicar sus conocimientos básicos en la catalogación, clasificación y encabezamientos de materia.

- Pro por cio nar al gu nos servi cios a los lec to res, ta les como: circu la ción o prés ta mo, con sul ta o in for ma ción de ma teriales básicos.

- Elaborar bibliografías descriptivas.

- Registrar y tabular los datos estadísticos de las bibliotecas y centros de información y documentación.

- Auxiliar en las labores de extensión bibliotecaria. ${ }^{24}$

De nuevo, en este aspecto encontramos la influencia de la ENBA en el perfilprofesiográfico des cri to en la IV Mesa del CNB, cu yos li nea mien tos coin ci den en su to ta li dad con los de la escuela ya citada, aunque expresados en otro orden y con otra redacción.

El plan de estudio de la Escuela incluye las asignaturas siguientes para biblioteconomía:

\section{Cuadro 1}

\section{Asignaturas de Biblioteconomía (Escuela Nacional de Biblioteconomía y Archivonomía)}

- Fundamentos y técnicas de la biblioteconomía

- Servicio a los lectores I

- Servicio a los lectores II

- Elementos de catalogación

- Elementos de clasificación
- Encabezamientos de materia

- Adquisición de materiales documentales

- Publicaciones periódicas

- Introducción a la bibliografía

La IV Mesa Re don da, sus cri ta por el CNB en 1984, re ci be una in fluen cia en el plan de la Es cue la. En el cua dro 2 se pre sen tan las comparaciones de las asignaturas propuestas por la Mesa Redonda mencionada y las incluidas en el plan de estudio de la ENBA.

\section{Cuadro 2}

Comparación: Escuela Nacional de Biblioteconomía y Archivonomía y Colegio Nacional de Bibliotecarios

\begin{tabular}{|l|l|}
\hline \multicolumn{1}{|c|}{ EN BA } & \multicolumn{1}{c|}{ CNB IV MESA } \\
\hline $\begin{array}{l}\text { Fundamentos y técnicas de } \\
\text { la biblioteconomía }\end{array}$ & \\
\hline Servicio a los lectores I & Préstamo \\
\hline Servicio a los lectores II & Consulta \\
\hline Elementos de catalogación & $\begin{array}{l}\text { Elementos de clasificación y } \\
\text { catalogación }\end{array}$ \\
\hline Elementos de clasificación & $\begin{array}{l}\text { Elementos de clasificación y } \\
\text { catalogación }\end{array}$ \\
\hline $\begin{array}{l}\text { Encabezamientos de mate- } \\
\text { ria }\end{array}$ & $\begin{array}{l}\text { Elementos de clasificación y } \\
\text { catalogación* }\end{array}$ \\
\hline $\begin{array}{l}\text { Adquisición de materiales } \\
\text { documentales }\end{array}$ & Adquisiciones \\
\hline Publicaciones periódicas & Publicaciones periódicas \\
\hline Introducción a la bibliografía & Introducción a la bibliografía \\
\hline & Extensión bibliotecaria \\
\hline & $\begin{array}{l}\text { Introducción a la biblioteco- } \\
\text { logía }\end{array}$ \\
\hline
\end{tabular}

* Es tas ma te rias inclu yen en sus con te ni dos te máticos, te mas se me jan tes en las asignaturas de la ENBA.

\section{Colegio de Bachilleres}

En el D.F. se encuentra el Colegio de Bachilleres ofreciendo laca pa ci ta ción para el tra bajo a los es tu dian tes del ba chille rato. Fue en 1980 cuan do se im ple men tó la ca pa ci ta ción es pe cífica en biblioteconomía, pero ésta surgió sin una planeación adecuada y sin particularintención de implantarla pero sí por el carácter bivalente asignado por la XIII Asamblea General de la ANUIES al Co le gio de Ba chi lle res de ser vir como ci clo propedéutico para la educación superior y simultáneamente capacitar a los alumnos para integrarse al trabajo al finalizar el bachillerato.

Laimplementación de la capacitación en biblioteconomíano fue el pro duc to de una in ves ti ga ción ob je ti va, más bién de índole muy parcial de:

- Mercado laboral (existencia de plazas vacantes)

-Interés de los alumnos del bachillerato sobre esta opción -Or ga nis mos que cap ta rían a sus egre sa dos para tra bajar en sus bibliotecas. 
Dado lo anterior, el perfil del egresado de la capacitación en bi blio te co no mía era am bi guo y casi ine xis ten te, lo cual ori ginó que en 1984 el Cen tro de Ca pa ci ta ción para el tra bajo (CECAT) del Co le gio de Ba chille res adop ta ra un nue vo per fil "el egresado de la capacitación en biblioteconomía es un profesio nis ta de ni vel in ter me dio, ca pa ci ta do para au xi liar en todo tipo de uni da des de in for ma ción, quien parti ci pa en ac ti vi dades de or ga ni za ción bi blio gráfica y circu la ción de los diferentes tipos de materiales, y en general, coad yuva en la localización, organización y recuperación de la información, sobre cualquier tó pi co queinteresa a diversos camposprofesionales y de investigación. Además registra y tabula datos estadísticos de interés para su centro de trabajo y colabora en la promoción de los servicios bibliotecarios a través de la orientación de usuarios en estrecha vinculación con los programas generales que establecen sus directivas". ${ }^{25}$

La capacitación técnica en el Colegio de Bachilleres ofrece diez opciones posibles de las cuales es obligatorio que el alum no eli ja una de és tas, ya sea las que ofre ce su pro pio plantel o algún otro, lo cual es una desventaja ya que si el alumno quie re cur sar una op ción que no exis ta en su plan tel tie ne que asistir al que imparta dicha capacitación, lo cual repercuteen el tiempo de traslado hacia el otro plantel; por lo tanto, el alumno se ve obligado a escoger entre las opciones que le ofre ce su plan tel, aun que nin gu na de ellas sea de su agra do.

Los plan te les que ofre cen la ca pa ci ta ción téc ni ca en bi blio teconomía son únicamente dos, el plantel 17 y el 18. En ellos tam bién se cuen ta con la op ción en con ta bi li dad, lo que in di ca que los alum nos pue den ele gir en es tos dos plan te les dos posibilidades: biblioteconomía o contabilidad. Si desean alguna otra, tendrían que dirigirse al plantel donde sea impartida la opción de su interés.

Dado lo anterior, se infiere que:

a) El alum no es co ge una de las dos op cio nes sin que al gu na de ellas le agrade.

b) El alum no toma la op ción que le re pre sen te me nos di fi cultades para él.

c) Elalum no toma la op ción que no in vo lu cre ma te má ti cas.

Nuestra experienciadocente en bachilleres puede corroborar lo investigado por Nava Figueroa respecto a lo mencionado en los in ci sos an te rio res; lo que lle va a con cluir que las ca pacitaciones en biblioteconomía no las toman los alumnos por inclinación vocacional, más aún, son una limitante ya que no existe la libre selección de la opción técnica, sino más bién considerada por cuestiones de:

a) No existir todas las opciones en cada plantel.

b) Fal ta de re cur sos para ofre cer las op cio nes en cada plan tel.

c) Cupo limitado en cada plantel donde se imparte la opción que el alumno desea cursar. d) Pér di da de tiem po al tras la dar se al plan tel don de se im par te la op ción que es co gió el alum no, si es que hubo cupo para él.

Por otro lado, re vi san do el plan de es tu dios de la op ción téc nica en biblioteconomía, vie ne a su mar se a las cues tio nes an tes ex pues tas que al prac ti car la do cen cia en ba chille res se pue de rescatar que sólo tres asignaturas cuentan con contenido programático, las res tan tes sólopresentanun contenidote mático con algún desglose de los subtemas.

Por lo señalado en los contenidos programáticos de las tres ma te rias, por la prác ti ca do cen te y por ha ber cur sa do la li cencia tu ra en biblio te co lo gía, el docen te se per ca ta de que di chas asignaturas son profundas y es ta rían me jor ubi ca das en el nivel su pe rior (como ejem plo, bas ta se ña lar la asig na tu ra ad ministración de bibliotecas) y no en el bachillerato técnico, ya que el alum no aún no tie ne la ca pa ci dad para com pren der algunos conceptos, además de considerar que cursan otras materias del bachillerato propedéutico (matemáticas, biología, química, etc.) que son las principales. Aunado a esto, habrá que de cir que la bi blio gra fía su ge ri da es de ni vel alto y con títu los en otro idio ma, el cual no ma ne ja el alum no de ba chi llerato.

As pec to im por tan te a con si de rares el he cho de que no exis ten prácticas en las bibliotecas donde el alumno puede formarse como técnico en el sentido más amplio. Las pocas prácticas que se realizan están desorganizadas y descoordinadas con las de más asig na tu ras y no son exi gi das por el pro pio Co le gio de Ba chi lle res, ya que tan to el plan de es tu dios como los programas no las señalan.

Con cor dan do con lo ex pues to por Nava Fi gue roa, ${ }^{26}$ podemos señalar lo siguiente:

a)El perfil del egre sa do de la ca pa ci ta ción téc ni ca en biblio teconomía coincide con el perfil propuesto por la IV Mesa Redonda del CNB en un $29 \%$

b) El contenido de las asignaturas de la capacitación técnica en biblioteconomía concuerda con lo propuesto por el CNB, en términos generales en más de un $50 \%$

La estructura del plan de estudios de la opción técnica en biblioteconomía tiene concordancia con el plan de estudio del ba chi lle ra to téc ni co de la ENBA, lo cual se ob ser va en el cuadro cuatro. Existen materias con contenidos temáticos semejantes, ${ }^{27}$ aunque presentan diferente nombre, lo cual nos permite inferir que el plan de estudio de la opción técnica impartida por la ENBA tuvo una influencia sobre el plan del Colegio de Bachilleres, dado que el plan ENBA es el antecedente del técnico en biblioteconomía.

Existe cierta semejanza entre las materias (excepto administra ción de bi blio te cas e in tro duc ción a la bi blio te co lo gía) impar ti das en el Co le gio de Ba chille res, in clu so exis te una asig natura del plan ENBA que guarda semejanza con dos asignaturas del Colegio de Bachilleres: "Servicio a los lectores II" (ENBA) tiene su contraparte en la de "Fuentes de In- 
for ma ción" y en la de "Ser vi cio a usua rios I" (CB), pero también los contenidos de es tas dos úl ti mas son muy se me jan tes, por lo que se po dría de cir que lo tra ta do en "Fuen tes de In formación" está incluido en la asignatura de "Servicios a usuarios I".

\section{Cuadro 3}

Asignaturas de biblioteconomía (Colegio de Bachilleres)

- Introducción a la biblioteconomía

- Fuentes de información

- Administración de bibliotecas

- Procesos técnicos I

- Procesos Técnicos II

- Técnicas bibliotecarias

- Servicios a usuarios I

- Servicios a usuarios II

\section{Cuadro 4}

Comparación: Escuela Nacional de Biblioteconomía y Archivonomía y el Colegio de Bachilleres

\begin{tabular}{|l|l|}
\hline \multicolumn{1}{|c|}{ ENBA } & \multicolumn{1}{c|}{ CB } \\
\hline \hline $\begin{array}{l}\text { Fundamentos y técnicas de } \\
\text { la biblioteconomía }\end{array}$ & \\
\hline Servicio a los lectores I & Servicio a usuarios II \\
\hline Servicio a Ios lectores II & $\begin{array}{l}\text { Servicio a usuarios I* / Fuen- } \\
\text { tes de información }\end{array}$ \\
\hline Elementos de catalogación & Procesos técnicos I \\
\hline Elementos de clasificación & Técnicas bibliotecarias* \\
\hline $\begin{array}{l}\text { Encabezamientos de mate- } \\
\text { ria }\end{array}$ & Técnicas bibliotecarias \\
\hline $\begin{array}{l}\text { Adquisición de materiales } \\
\text { documentales }\end{array}$ & Procesos técnicos II \\
\hline Publicaciones periódicas & Servicios a usuarios I* \\
\hline Introducción a la bibliografía & $\begin{array}{l}\text { Administración de bibliote- } \\
\text { cas }\end{array}$ \\
\hline & $\begin{array}{l}\text { Introducción a la biblioteco- } \\
\text { logía }\end{array}$ \\
\hline
\end{tabular}

* Estas asig naturas in clu yen los con te nidos te máti cossemejan tes a varias asignaturas de la ENBA.

\section{Colegio de Ciencias y Humanidades/UNAM}

ElCo le gio de Cien cias y Hu ma ni da des de la Uni ver si dad Nacional Autónoma de México, ofrece también el bachillerato en el Dis tri to Fe de ral y brin da a los alum nos que lo de seen, la posibilidad de contar con una formación para integrarse al trabajoproductivo a través de los cur sos que es ta ble ce el Departamento de Opciones Técnicas, el cual diseña, promueve, evalúa y desarrolla los programas de formación profesional para el tra ba jo. Di chos pro gra mas son rea li za dos con las partes teó ri cas y prác ti cas en los lu ga res don de se de sa rro llan las actividades específicas de la opción técnica.

El diseño de los programas de estas opciones está basado en una investigación del área, la cual fue realizada por el $\mathrm{CCH}$ teniendo los propósitos siguientes: $:^{28}$

Detectar la demanda de recursos humanos

- Establecer los objetivos generales del programa

- Definir los contenidos temáticos

- Diseñar las actividades prácticas

- Es ti mar el tiem po para ellogrode los obje ti vos del curso.

En el avan ce de di cha in ves ti ga ción del CCH se rea li za ron entrevistas en el área, tanto en el sector académico como en el mercado de trabajo; por lo que cabe señalar lo siguiente:

a) Es in du da ble que en las bi blio te cas hace fal ta per so nal au xi liar para de sa rro llar las ac ti vi da des ru ti na rias de ser vi cios al público, del proce sofísico, man te ni mien to deca tálogos, etc., pero hay que tomar en cuenta la cantidad de bibliotecasexistentes y a cuántas de ellas les falta personal.

b) El mer ca do de tra ba jo se re fie re a cuán tas son y la exis ten cia de plazas vacantes, las cua les no exis ten, a pe sar de que ha cen falta. Por ejemplo, en el caso de la UNAM, ésta no absorve a los egre sa dos de su pro pio ba chille ra to con la op ción téc nica en bibliotecología, ya que la Universidad, como otras instituciones (UAM, UPN, CB) realiza la contratación de su personal para las bi blio te cas a tra vés del sin di ca to, lo que re pre sen ta que dicho sindicato controla y propone a los candidatos para las plazas vacantes; en con secuencia, los can didatoscomúnmente son trabajadores de laUNAM sin di calizados, loque re presen ta que harán uso del llamado escalafón.

Por otro lado, el re qui si to para las pla zas de bi blio te ca rio de la UNAM exi ge el ba chi lle ra to ter mi na do sin pe dir que éste sea bachillerato técnico en bibliotecología.

Lo men ciona do en los in ci sos an te riores no pare ce es tar reflejado en dichas investigaciones ya que un bachiller egresado delCCH con op ción téc ni ca en bi blio te co lo gía no pue de as pirar a tra ba jar en las bi blio te cas ni de la pro pia UNAM, ya que ten drá que di ri gir se a la bol sa de tra ba jo del sin di ca to, ya sea de la UniversidadNacional o a la de otra ins ti tu ción, en cuyo caso tendrá que seguir las instancias correspondientes con el an te ce den te de que la prio ri dad, ante todo, la tie nen los tra bajadores postulados por el sindicato. Tal situación plan tea una incongruencia ya que si la UNAM prepara al bachiller para integrarse al trabajo produc tivo, éste ten drálos proble mas de fal ta de pla zas va can tes y en fren tar se a una con tra ta ción a través de medios sindicales.

Por lo que res pec ta al di se ño del pro gra ma de la op ción téc nicaen bibliotecología, elDepartamen to deOpciones Técnicas de la Dirección de la Unidad Académica del Ciclo de Bachillerato del Colegio de Ciencias y Humanidades se propuso po ner en prác ti ca los acuer dos de la IV Mesa Re don da del Colegio Na cio nal de Bi blio te ca rios so bre el ni vel téc ni co en bibliotecología. 
El programa reestructurado de esta opción técnica presenta dos semestres lec ti vos, 120 horas teórico-prácticas, 112 horas de ac ti vi da des prác ti cas y un sis te ma de evalua ción de fini do y sistematizado.

El programa del $\mathrm{CCH}$, para la opcióntécnicaenbibliotecología cuenta con una organización y coordinación de prácticas muy bien rea li za da, en las cua les los alum nos pue den per manecer en el ambiente laboral de la biblioteca, lo cual les permite ubicarse en el desarrollo de las actividades en forma directa.

El programa de la opción técnica está constituido por cinco uni da des, las cua les se dan a co no cer en el si guien te cua dro.

\section{Cuadro 5}

Unidades de Bibliotecología

(Colegio de Ciencias y Humanidades)

- Las bibliotecas en el contexto social

- Procesos técnicos

- Publicaciones periódicas y materiales audiovisuales

- Servicio a usuarios

- Extensión bibliotecaria

La es truc tu ra ción del pro gra ma, así como la bi blio gra fía para cada par te del mis mo, está to tal men te ape ga da a lo pro pues to por la IV Mesa Re don da del CNB, lo cual mues tra las mis mas fallas señaladas al CNB en el capítulo II de este trabajo.

Elprogramade la op ción téc ni ca en biblio te cono mía presenta algunas semejanzas con el contenido temático de sus unidades, con las asig na tu ras del ba chille ra to téc ni co en biblio te cono mía de la ENBA; y a su vez, la asig na tu ra "Fuen tes y téc nicas de bi blio te co no mía" de la ENBA, no tie ne su con tra par te en la op ción téc ni ca del CCH. La co rres pon den cia de las asignaturas en contenidos temáticos puede verse en el cuadro 6 . Cabe re mar car que, aun que tie nen di fe ren tes nom bres en cada asig na tu ra o uni dad de la op ción téc ni ca, los con te ni dos te máticos son se me jan tes, lo que nos lle va a con cluir que subs tancialmente son iguales salvo algunos detalles menores.

Es ne ce sa rio se ña lar que en elCCH el to mar la op ción téc ni ca representa un interés personal del alumno, ya que no se le obli ga, por el pro pio plan de es tu dios, a to mar una op ción técnica, lo que podría significar que los alumnos que toman la opción técnica en bibliotecología tienen un aparente interés vocacional.

\section{Cuadro 6}

Comparación: Escuela Nacional de Biblioteconomía y Archivonomía y el Colegio de Ciencias y Humanidades

\begin{tabular}{|l|l|}
\hline \multicolumn{1}{|c|}{ ENBA } & \multicolumn{1}{c|}{ CCH } \\
\hline \hline $\begin{array}{l}\text { Fundamentos y técnicas de } \\
\text { la biblioteconomía }\end{array}$ & \\
\hline \hline Servicio a los lectores I & Servicios a usuarios* \\
\hline Servicio a los lectores II & Servicios a usuarios* \\
\hline Elementos de catalogación & Procesos técnicos* \\
\hline
\end{tabular}

\begin{tabular}{|l|l|}
\hline \multicolumn{1}{|c|}{ ENBA } & \multicolumn{1}{c|}{ CCH } \\
\hline \hline Elementos de clasificación & Procesos técnicos ${ }^{*}$ \\
\hline $\begin{array}{l}\text { Encabezamientos de mate- } \\
\text { ria }\end{array}$ & Procesos técnicos \\
\hline $\begin{array}{l}\text { Adquisición de materiales } \\
\text { documentales }\end{array}$ & Procesos técnicos* \\
\hline Publicaciones periódicas & $\begin{array}{l}\text { Publicaciones periódicas y } \\
\text { materiales audiovisuales }\end{array}$ \\
\hline Introducción a la bibliografía & $\begin{array}{l}\text { Las bibliotecas en el contex- } \\
\text { to social }\end{array}$ \\
\hline & Extensión bibliotecaria \\
\hline
\end{tabular}

* Es tas asigna tu ras in clu yen los con te ni dos te má ti cos se me jan tes a varias asignaturas de la ENBA.

\section{Anteproyecto de Educación Bibliotecológicaen Tabasco: el caso del Nivel Técnico}

En el Es ta do de Ta bas co se pro po ne la im ple men ta ción del nivel técnico en bibliotecología. En él existen 773 bibliotecas en las cuales se encuentran laborando 7 profesionales en bibliotecología, 185 profesionales de otras áreas, 695 de ellos con ba chille ra to o equi va len te, 283 que cuen tan con una es colaridad de secundaria, y sólo 27 que terminaron su primaria; haciendo un total de 1198 empleados del sistema bibliotecario del Estado. ${ }^{29}$

El anteproyecto de implementación de un bachillerato técnico, se gún sus au to res, ${ }^{30}$ es el re sul ta do de un diag nós ti co de los servicios bibliotecarios en Tabasco, en el cual la mayoría de los trabajadores bibliotecarios del Estado consideran la formación de este nivel técnico.

El re por te de este diag nós ti co no men cio na el nú me ro de plazas va can tes exis ten tes o que exis ti rán para los egre sa dos del bachillerato técnico; más bién se centra sólo en dos núcleos para que po sean el ni vel téc ni co en bi blio te co lo gía de ma ne ra formal hacia quienes va dirigido este anteproyecto:

a) Los que tienen estudios de secundaria (283)

b) Los que tienen bachillerato (695)

Sin embargo, consideramos que los estudiantes de los dos gru pos an te rio res ya se cuen tran la bo ran do en las bi blio te cas, y por lo tanto no es personal nuevo que en tre a la bo rar en las mis mas; más bien, los cur sos for ma rían par te de una ca pa ci tación que no es entendida como tal.

Dado los datos manejados en el an te proyec tocabría unain terrogan te: ¿A to dos los tra baja do res sus cep tibles de in gre sar a esta op ción (los de se cun da ria y ba chille ra to) les in te re sa realmen te ob tenerun ba chille ra to téc ni co en bibliote conomía? Si en las propias entrevistas al personal estos señalaban que "la asignación de actividades bibliotecarias se consideraba un castigo administrativo", 31 significa que no existe interés ex- 
preso. El an te proyec to propone dos vertien tes del ba chille rato técnico:

a) Sistema escolarizado para los bibliotecarios en servicio, que cum plien do con los re qui si tos de in gre so en gru pos de 30 a 40 y con una beca se ins cri ban a él, lo cual co rres pon de a 283 em plea dos que cu bren la se cun da ria y que po drían in gre sar al bachillerato.

b) Sis te ma se miescolariza do, el cual aten de ráa quie neshayan con clui do o es tén cur san do el ba chille ra to y que sólo cum plan con las asignaturas correspondientes a bibliotecología. Esto estaría ubicado para los 695 empleados con bachillerato.

En con cor dan cia con lo an te rior el an te proyec to Tabas coestá principalmente dirigido a los que trabajan en las bibliotecas, si tua ción que nos per mi te re fle xio nar si se ría me jor un adiestramiento bien realizado en el propio centro de trabajo y que in clu ye ra to das las ac ti vi da des de la biblio te ca. Lo an te riorresultaría más acertado dadas las características del personal, por ser menos costoso y además podría ser obligatorio para todo el personal en funciones.

Enre la ción al pro gra ma de edu cación bi blio te co ló gi caen Tabasco, uno de los obje ti vos señala dos es el de "for marbibliotecarios a nivel me dio su perior parasatisfacer las necesidades de organización y desarrollo de las bibliotecas escolares, especializadas, universitarias y públicas." ${ }^{\text {31 }}$ Objetivo totalmente desfasado de acuerdo a los principios generales que norman la existencia del bachillerato técnico.

Asítam bién, el an te pro yec to no men cio na cuál es la de man da real de re cur sos hu ma nos en ra zón de lo que el pro gra ma pueda satisfacer dadas las demandas de plazas en las bibliotecas del Estado.

Datore le van te locons ti tu yeel nú me rode 695 trabaja dores de la biblioteca que ya cuentan con el bachillerato y que dada la pro pues ta son con si de ra dos como can di da tos rea les para realizar el bachillerato técnico en bibliotecología, situación que nos hace pensar en una regresión académica para tales emplea dos ya que és tos bien po drían as pi rar a una li cen cia tu ra en biblioteconomía o cualquier otra, puesto que ya cuentan con el requisito para el ingreso a un nivel superior.

De la misma manera, los requisitos de ingreso para cursar el ba chille ra to téc ni co tal como se pro po ne no son po si bles porque no es fá cil te ner una me di ción ob je ti va o com pro bar el interés por el serviciobibliotecario, como es el requisitosolicitado. También es importante hacer hincapié en que a los egresados de este programa se les pide cubrir 480 horas de servicio social y además, presentar un informe. Tal petición no es característica de un bachillerato técnico; en el sistema edu ca ti vo na cio nal éste es un re qui si to para los ni ve les profesionales. Como ejem plo bas te ci tar que en el D.F. las ins ti tuciones que ofre cen el bachille ra to téc nicoen biblio te conomía no solicitan ninguno de estos requisitos.

Para la es truc tu ra del plan de es tu dio se con si de ra ron las reco- mendaciones de la IV Mesa Redonda del CNB.

El bachillerato se com po ne de ma te rias en el área de cien cias sociales, específicas del área bibliotecológica, de carácter obligatorio y seminarios complementarios opcionales.

Cabe señalar que los seminarios en el sentido más amplio de la palabra son ofrecidos en los últimos semestres de la licencia tu ra y en el pos gra do, no sien do con ve nien te in tro du cir los en el nivel medio superior puesto que el alumno aún no conceptualiza ni profundiza muchas de sus ideas.

El plan de estudio con tie ne 13 asig na tu ras, no nue ve como lo pro pone elCNB, y las cua tro ma te rias adi cio na les obe de cen a que el "perfil que presupone la normatividad parte del hecho de formar técnicosauxiliares, y aquí se pretende, atendiendo anues trarealidad, el producirtéc nicosresponsables". Es necesario añadir a lo anterior que no puede existir una relación ca sual en tre el nú me ro de ma te rias que se im par ta al téc ni co y a la responsabilidad de éste. Si esta relación fueraverdadera, sería mejor impartir 20, 30 ó 40 materias para que el técnico duplicara, triplicara, o cuatriplicara su responsabilidad.

A con ti nua ción se des glo san las asig na tu ras del plan de es tut dio propuesto:

\section{Cuadro 7}

Asignaturas de Bibliotecología (Anteproyecto Tabasco)

- Introducción a la bibliotecología

- Elementos de catalogación I

- Elementos de catalogación II

- Elementos de clasificación I

- Elementos de clasificación II

- Adquisición de materiales documentales

- Publicaciones periódicas

- Servicios a los lectores I

- Servicios a los lectores II

- Introducción a la bibliografía

- Fuentes de Información I

- Fuentes de Información II

- Extensión bibliotecaria

\section{Cuadro 8}

Comparación: Escuela Nacional de Biblioteconomía y Archivonomía y el Anteproyecto de Educación Bibliotecológica en Tabasco

\begin{tabular}{|l|l|}
\hline \multicolumn{1}{|c|}{ ENBA } & \multicolumn{1}{|c|}{ Anteproyecto Tabasco } \\
\hline \hline $\begin{array}{l}\text { Fundamentos y técnicas de } \\
\text { la biblioteconomía }\end{array}$ & \\
\hline Servicio a los lectores I & Servicio a los lectores I \\
\hline Servicio a los lectores II & $\begin{array}{l}\text { Servicio a los lectores II / } \\
\text { Fuentes de información I y } \\
\text { Fuentes de información II }\end{array}$ \\
\hline Elementos de catalogación & $\begin{array}{l}\text { Elementos de catalogación I } \\
\text { y Elementos de catalogación } \\
\text { II }\end{array}$ \\
\hline
\end{tabular}




\begin{tabular}{|l|l|}
\hline \multicolumn{1}{|c|}{ ENBA } & \multicolumn{1}{|c|}{ Anteproyecto Tabasco } \\
\hline \hline Elementos de clasificación & $\begin{array}{l}\text { Elementos de clasificación I } \\
\text { y Elementos de clasifica- } \\
\text { ción II }\end{array}$ \\
\hline $\begin{array}{l}\text { Adquisición de materiales } \\
\text { documentales }\end{array}$ & $\begin{array}{l}\text { Adquisición de materiales } \\
\text { documentales }\end{array}$ \\
\hline Publicaciones periódicas & Publicaciones periódicas \\
\hline Introducción a la bibliografía & Introducción a la bibliografía \\
\hline & Extensión bibliotecaria \\
\hline & $\begin{array}{l}\text { Introducción a la biblioteco- } \\
\text { logía }\end{array}$ \\
\hline
\end{tabular}

* Las asig na tu ras de Fuen tes de in for ma ción I y II, se in fie re que caen en Servicio a los lec to res II, y a que en el Cole gio de B a chille res la asig na tu ra de Fuen tes de in for ma ción está in cluí da en esta ma te ria y tie nen el mis mo nombre, sólo que se da en dos semestres. (Cuadro 4).

Los pro gra mas de es tu dio de la ENB A y del An te pro yec to Tabascosonsemejantes, salvoen las cuatro materias siguientes:

Extensión bibliotecaria

Fuentes de Información I

Fuentes de Información II
Introducción a la bibliotecología

Las ma te rias an te rio res no tie nen su con tra par te for mal en las de la ENBA, excepto la de Fuentes de Información.

Dada la re vi sión de este plan de es tu dio en re la ción con los demás, inferimos que:

a) Las materias de "Fuentes de Información I y II" del Anteproyecto Tabasco, tienen el mismo nombre que la materia "Fuentes de Información" impartida en el Colegio de Bachilleres.

b) Las ma te rias "Fuen tes de In for ma ción I y II" for man par te de la asig na tu ra "Ser vi cio a los Lec to res II" que se im par te en la ENBA.

En cuanto al perfil del egresado del anteproyecto Tabasco, éste con cuer da con el egre sa do de la ENBA, con al gu nas di ferencias mínimas, por lo que substancialmente es el mismo. Por lo anteriormente expuesto podemos concluir que el plan ENBA tuvo influencia sobre la estructuración del anteproyecto Tabasco, principalmente, incluyendo además, partes del plan del Co le gio de Ba chille res y de lo pro pues to por la IV

Cuadro 9

Comparación: ENBA-CB-CCH-Anteproyecto Tabasco-CNB

\begin{tabular}{|c|c|c|c|c|}
\hline ENBA & $C B$ & $\mathrm{CCH}$ & $\begin{array}{c}\text { Anteproyecto } \\
\text { Tabasco } \\
\end{array}$ & $\mathrm{CNB}$ \\
\hline \multicolumn{5}{|l|}{$\begin{array}{l}\text { Fundamentos y técni- } \\
\text { cas de la bibliotecono- } \\
\text { mía }\end{array}$} \\
\hline Servicio a los lectores I & Servicio a usuarios II & Servicio a usuarios & Servicio a los lectores I & Préstamo \\
\hline $\begin{array}{l}\text { Servicio a los lectores } \\
\text { II }\end{array}$ & $\begin{array}{l}\text { Servicio a usuarios I / } \\
\text { Fuentes de informa- } \\
\text { ción }\end{array}$ & Servicio a usuarios & $\begin{array}{l}\text { Servicio a los lecto- } \\
\text { res II, Fuentes de infor- } \\
\text { mación I y Fuentes de } \\
\text { información II }\end{array}$ & Consulta \\
\hline $\begin{array}{l}\text { Elementos de catalo- } \\
\text { gación }\end{array}$ & Procesos técnicos I & Procesos técnicos & $\begin{array}{l}\text { Elementos de catalo- } \\
\text { gación I y Elementos } \\
\text { de clasificación II }\end{array}$ & $\begin{array}{l}\text { Elementos de clasifica- } \\
\text { ción y catalogación }\end{array}$ \\
\hline $\begin{array}{l}\text { Elementos de clasifica- } \\
\text { ción }\end{array}$ & Técnicas bibliotecarias & Procesos técnicos & & $\begin{array}{l}\text { Elementos de clasifica- } \\
\text { ción y catalogación }\end{array}$ \\
\hline $\begin{array}{l}\text { Encabezamientos de } \\
\text { materia }\end{array}$ & Técnicas bibliotecarias & Procesos técnicos & $\begin{array}{l}\text { Adquisición de mate- } \\
\text { riales documentales }\end{array}$ & Adquisiciones \\
\hline $\begin{array}{l}\text { Adquisición de mate- } \\
\text { riales documentales }\end{array}$ & Procesos técnicos II & $\begin{array}{l}\text { Publicaciones periódi- } \\
\text { cas y material audiovi- } \\
\text { sual }\end{array}$ & $\begin{array}{l}\text { Publicaciones periódi- } \\
\text { cas }\end{array}$ & $\begin{array}{l}\text { Registro y control de } \\
\text { publicaciones periódi- } \\
\text { cas }\end{array}$ \\
\hline $\begin{array}{l}\text { Publicaciones periódi- } \\
\text { cas }\end{array}$ & Servicio a usuarios I & & $\begin{array}{l}\text { Introducción a la biblio- } \\
\text { grafía }\end{array}$ & $\begin{array}{l}\text { Introducción a la biblio- } \\
\text { grafía }\end{array}$ \\
\hline \multirow[t]{4}{*}{$\begin{array}{l}\text { Introducción a la biblio- } \\
\text { grafía }\end{array}$} & & & $\begin{array}{l}\text { Introducción a la biblio- } \\
\text { tecología }\end{array}$ & $\begin{array}{l}\text { Introducción a la biblio- } \\
\text { tecología }\end{array}$ \\
\hline & $\begin{array}{l}\text { Introducción a la biblio- } \\
\text { teconomía }\end{array}$ & & & \\
\hline & $\begin{array}{l}\text { Administración de bi- } \\
\text { bliotecas }\end{array}$ & $\begin{array}{l}\text { Las bibliotecas en el } \\
\text { contexto social }\end{array}$ & & \\
\hline & & Extensión bibliotecaria & Extensión bibliotecaria & Extensión bibliotecaria \\
\hline
\end{tabular}


Mesa Redonda del CNB.

Para concluir este capítulo, diremos que los egresados de la capacitación técnica en biblioteconomía no son contratados confacilidaden los gran des cen tros biblio te carios delDis trito Fe de ral (SEP, UNAM, UPN, CB, UAM) de bi do a que los sindicatos de cada una de estas instituciones cubren las plazas vacan tes sin dar po si bi li dad a la bi blio te ca de se lec cio nar a su personal no profesional.

\section{MERCADO DE TRABAJO}

Como ya se ha vis to, ha ha bi do una fal ta de es tu dio de mer cado de trabajo que con tem pla las po sibi li da des de con tra ta ción de los egre sa dos de esta op ción téc ni ca; es así que con el propó si to de apo yar el análi sis de los do cu men tos uti li za dos para el desarrollo del trabajo, se diseñó un cuestionario (anexo) que nos per mi tie ra in da gar al gu nos as pec tos de los egre sa dos delbachillerato téc ni co en bi blio te co no mía con res pec to a su ubi ca ción en diferen tes cen tros biblio te carios delDis trito Federal.

Para la aplicación del cuestionario se decidió encuestar a los em plea dos que se en con tra ban tra ba jan do en las áreas de servicio, únicamente, de tres sistemasbibliotecarios: Biblioteca Central de la UNAM, Biblioteca Pú bli ca de Mé xi co y las Bibliotecas pertenecientes al Instituto Politécnico Nacional en su unidad Casco de Santo Tomás. Se consideraron estas bibliotecas debido a que son, en el D.F., algunos de los más grandes captadores de personal para el trabajo bibliotecario.

Con la aplicación de este cuestionario se pretendía tener una idea general de la cap ta ción de los ba chi lle res téc ni cos en biblioteconomía que han egre sa do de las dis tin tas es cue las que imparten este nivel de educación media superior en nuestro país, y re for zar con ello los re sul ta dos del análi sis de los do cumentos que se señalan con relación al bachillerato técnico.

La aplicación de este cuestionario fue de manera directa en los centros de trabajo. Su contenido consta de preguntas cerradas, previa explicación del objetivo del cuestionario por parte de los encuestadores.

El total de encuestados ascendió a 117 empleados, cuyos resultados analizamos a continuación:

El ni vel de es tu dio de los en cues ta dos re ve la ba que el 5.9\% (7 de ellos), cuentan con un nivel de secundaria; el 23\% (27 de éstos), cuentan con bachillerato y el $70.9 \%$ restante (83 emplea dos) tie nen un ni vel de li cen cia tu ra. Cabe acla rar que este úl ti mo porcen ta je in clu ye a los es tu dian tes que aún cur san los úl ti mos se mes tres de la li cen cia tura. (vercua dro 1 del ane xo).

Del $100 \%$ encuestado (117), el $24.7 \%$ (29) cuentan con bachille ra to con op ción téc ni ca en bi blio te co no mía y el $69.23 \%$ res tan te (81), no cuen tan con esta op ción; cabe se ña lar en este caso que el 5.9\% (7) restante está representado por los emplea dos que úni ca men te tie nen se cun da ria. (Ver cua dro 2 del anexo).
Es im por tan te ana li zar las ra zo nes por las cua les los 29 ba chilleres técnicosinforman haberestudiado esta opción técnica, y en orden de importancia se ubican las siguientes razones:

- Porque ya se encontraban trabajando en una biblioteca $(13.7 \%)$

- En el rubro de otras ra zo nes, la de ma yor im por tan cia fue la inquietud de conocer la carrera $(13.7 \%)$

- Por influencia de familiares y amigos (13.7\%)

- Porque era la única opción, a sugerencia del orientador vocacional, y por un interés personal (10.3\%)

Se nota en estas respuestas que la orientación vocacional no ocu pa un lu gar im por tan te como de bie ra es perar se, si aten demos a que es uno de los objetivos del bachillerato técnico el despertar tempranamente la vocación del estudiante. (Ver cuadro 3 del anexo).

De los 29 ba chille res téc ni cos, el 48.2\% (14) re por ta ha ber hecho sus es tu dios en la ENBA; el $21 \%$ (6) en el Co le gio de Bachilleres; el 24\% (7) en el CCH-UNAM, y el 7\% (2) no respondió (Ver cuadro 4 del anexo).

De estos bachilleres técnicos, un alto porcentaje son egresados de la ENBA, que es la ins ti tu ción más an ti gua del país en ofrecer el bachillerato técnico en biblioteconomía.

Al indagar si estos 29 bachilleres técnicos consideraban que el hecho de haber cursado la opción técnica en biblioteconomía ha bía in flui doen su con tra ta ción, los re sul ta dos mues tran que el $75.8 \%$ (22 de ellos) asílo con si de ra ban, mien tras que el $17.2 \%$ (5) res pon dió que no; el $6.8 \%$ (2) se abs tu vo de res ponder (Ver cuadro 5 del anexo).

De be mos con si de rar que esta res pues ta de pen de de la subje tividad del contratado (bachiller técnico) y no del contratante, ya que no es re qui si to la bo ral con tar con el ba chille ra to téc nico en biblioteconomía para ingresar como trabajador a la biblioteca. Habría que considerar la opinión del contratante a esta res pues ta, lo cual ayu da ría a in fe rir con ma yor cla ri dad la aseveración de los encuestados.

De los 83 trabajadores que cuentan con estudios de licenciatura, el $60.2 \%$ (50) re por ta ron haber cursado o es tar cursan do una licenciatura en biblioteconomía, y el resto, es decir, el $39.7 \%$ (33), re por ta ha ber he cho sus es tu dios en una dis ci plina distinta a la biblioteconomía. Con relación al $100 \%$ encuestado(117), es tos 50 tra baja do res con es tu dios su periores en biblioteconomíare presentan el $42.7 \%$, loquesig nificaque un alto porcentaje de los encuestados ha cursado o está cursando es tu dios de li cen cia tu ra en bi blio te co no mía. (Vercuadro 6 del anexo).

Ahora bien, si analizamos la razón por la cual estos empleados (50) han cur sa do o es tán cur san do sus es tu dios de bi blioteconomía, podremos ver que el $32 \%$ (16), respondieronque 
les gustaba la dis ci pli na; otro $24 \%$ (12), re co no ció la in fluencia de fa mi lia res y ami gos; y un 18\% (9) era de bi do a que habían cur sa do el ba chille ra to téc nico en biblio te co no mía. Este dato nos sir ve para re fle xio nar que solo el $31 \%$ (9) de los que han cursa do el ba chille ra to téc nicoen biblio te co no mía(de 29 de ellos) consideraron la acreditación de la opción técnica para continuar su licenciatura en biblioteconomía. Por otra par te, es no ta ble la in fluen cia que tie ne la fa mi lia y ami gos en la elección de la carrera, ya que esto está representado en un $41.3 \%$ (12) con respecto a los 29 que repondieron haber cursa do su ba chille ra to téc ni co con esta op ción (Ver cua dro 7 del anexo).

Re sul taim portan te que de 50 em plea dos que es tán cursan doo han cursado la licenciatura en biblioteconomía, sólo el $28 \%$ (14 de ellos) han realizado el bachilleratocon opción técnica en la es pe cia li dad, y el $72 \%$ (36) res tan te ha cur sa do un ba chillerato general.

Si ana li za mos las razo nes que in di can los 14 que han cur sa do la op ción téc ni ca en bi blio te co no mía, por la cual han es tu dia do o están estudiando la licenciatura en biblioteconomía, veremos que el 50\% (7) es porque han cursado el bachillerato téc ni co en biblio te cono mía. Conigual porcen taje se reflejael gusto por la disciplina.

$\mathrm{Al}$ analizar estos datos, se esperaba por lo menos contar con un $95 \%$ de aque llos egre sa dos del ba chille ra to téc ni co que ingresaran a la licenciatura en la mismadisciplina, dado que se es pe ra ría, de igual ma ne ra que se cum pla con otro de los ob jeti vos del ba chille ra to bi valente, ade más de mo tivar al alum no en las actividades propias de la biblioteconomía.

\section{CONCLUSIONES Y RECOMENDACIONES}

1o. Si la preparación técnica en el bachillerato es independiente de su vinculación con el mercado laboral, sería mejor establecer un bachillerato propedéutico fuerte, eliminando aque llas op cio nes que, como bi blio te co no mía, son una ca pa citación indispensable para una posible incorporación al trabajo, ya que los que logran obtener una plaza lo hacen independientemente de la preparación técnica que posean, capacitándose en el trabajo.

2o. Se recomienda establecer una ca rre ra a ni vel de pro fe sional téc ni co vin cu la da con el merca do la bo ral del sec tor oficial pues in me dia ta men te se nota una in con gruen cia en tre las partes educativas que planifican y promueven estas opciones y las partes encargadas de otorgar empleo en las bibliotecas y unidades de información del sector oficial.

3o. Las bases para crear las opciones técnicas no contemplan el mercado laboral de manera objetiva ya que no consideran que las plazas están con tro la das por los sin di ca tos, por lo que los egresados del bachillerato técnico no son captados en las bibliotecas. 4o. En términos generales, el objetivo que se señala para la op ción téc ni ca de ofre cer una orien ta ción vo ca cio nal tem prana al alumno no se cumple.

5o. El plan de es tu dio del ba chi lle ra to téc ni co de la ENBA, influyó en los planes de estudio del $\mathrm{CCH}$, en los del Colegiode Ba chille res y en los del An te pro yec to Ta bas co y, de igual manera, en las propuestas de la IV Mesa Redonda del CNB.

6o. Los contenidostemáticos de la gran ma yo ría de las ma terias de los diferentes planes de estudio analizados son muy profundos para ser impartidos en el bachillerato.

7o. La bibliografía recomendada para las asignaturas que constituyen el plan de estudios de estas opciones técnicas es sumamente especializada presentándose en varios casos en otros idiomas.

8o. Los centros de empleo no exigen al contratarunbachillera to téc ni co en bi blio te co no mía. Se pide úni ca men te el ba chillerato general.

9. Las op cio nes téc ni cas no de ben plan tear se para nú cleos de em plea dos que yaes tén la bo ran do en las bi blio te cas (caso Tabas co), ya que esto co rres pon de ría pro pia men te a una ca pacitación.

10o. Las prác ti cas para la op ción téc ni ca no es tán ple na men te contempladas.

11o. Las recomendaciones de la IV Mesa Redonda del CNB son consideradas en la estructura de los planes de estudio de las opcionestécnicas, aun cuan doés tas re ba san el al can ce de un bachillerato.

12o. Existe un notable tras la pe en los con te ni dos míni mos de las asignaturas técnicas de biblioteconomía que se imparten, tan to en la li cen cia tu ra como en el ni vel téc nico, sig nifican do esto una falta de planeación en los distintos niveles en que debe enseñarse la biblioteconomía.

13o. Es recomendable que la capacitación técnica se ubique en una ac ti vidad de ter mina da de la bi blio te ca y no tra te de formar técnicos con conocimientos demasiado generales que van más allá del objetivo de la capacitación técnica.

14o. Las op cio nes téc ni cas en bi blio te co no mía no han re suel to la ca ren cia de per so nal téc ni co ca li fi ca do para las bi blio tecas.

15o. El nú cleo bá si co de la cu rrícu la de las op cio nes téc ni cas, es de ma sia do ele va do con res pec to a lo que se es pe ra del egresado.

16o. En las re co men da cio nes del CNB exis te una no ta ble discrepancia entre los contenidos mínimos del núcleo básico y las actividades no profesionales que se supone deberealizar el técnico en biblioteconomía. 
17o.Por todo lo an tes se ña la do, se re co mien da que el Cole gio Nacional de Bibliotecarios efectúe una rigurosa revisión de las propuestas de su IV Mesa Redonda, ya que ésta sirve como parámetro en la revisión, reestructuración y diseño de nuevos planes de estudio para la opción técnica, cuando en ella existe una serie de notables discrepancias.

\section{REFERENCIAS}

1. Nava Fi gue roa, Bal fre.Reestructuracióndelacapacitaciónespecíficaenbiblioteconomíaimpartidaenel Cole gio de Bachilleres. Mé xi co: El Au tor, 1989. p. 1. Te sis (Li cen cia do en Bi blioteconomía) - ENBA, 1989.

2. Es pinosa Suñer, En rique.Educaciónmediasuperior: la Escuela NacionalPreparatoria. México : UNAM, 1979. pp. 8-10.

3. Rangel Guerra, Alfonso. La educación superior en México. México : El Colegio de México, 19179. p. 240.

4. México.PresidenciadelaRepública.Cuartoinformede gobierno. Méxi co: La Pre si den cia, 1986. pp. 273-274.

5. Espinosa. Op. Cit. pp. 8-10.

6. México.Secretaría deEdu caciónPública. Subsecretaría deEducacióne In vestigación Tec no ló gica. Escuelas ycarrerasdeeducacióntecnológica: catálo go 1986-87 Mé xi co:La Se cre ta ría, 1986. pp. 33-41.

7. Nava. Op. Cit. p. 14.

8. Diaz Santana, Gilberto. "Niveles medio superior: bachillerato técnico en biblioteconomía". En: Bibliotecas y Archivos. n. 9 (1978). pp. 75-82.

9. Sa las Es tra da, Eduar do. "Pla nes y pro gra mas de es tu dio de la Es cue la Na cio nal de Bi blioteconomía y Ar chi vo no mía". En: Jor na das Me xi ca nas de Bi blio te co no mía(7a. : 1974 : Que ré taro, Qro.). Memorias. pp. 79-84. México : AMBAC, 1976.

10. Universidad Nacional Autónoma de México. Colegio de Ciencias y Humanidades.Direc ción de la Uni dad Aca dé mi ca del Cic lo Ba chille ra to. El bachillerato del Colegio de Cien cias y Humanidades: información para profesores. México :La Universidad, 1988. p. 14.

11. Morales Campos, Estela. “Opcióntécnicaen bibliotecología ani velbachillerato”. En: Bibliotecas y Archivos. n. 9 (1979). pp. 123-130.

12. Nava. Op. Cit. p. 9

13. Mesa Re don da so bre For ma ción de Re cur sos Hu ma nos (4a. : 1984 : Mé xi co, D. F.). IV Mesa redonda sobreformaciónderecursoshumanos: op cióntécnica.p. 2. Mé xi co: Co le gio Na cional de Bibliotecarios, 1985.

14. Mesa Re don da so bre For ma ción de Re cur sos Hu ma nos (2a. : 1981 : Oax te pec, Mor.).II Mesa redonda sobreformaciónderecursoshumanos: licenciatura. 1 v. Pág. va ría. Méxi co : Co le gio Nacional de Bibliotecarios; AMBAC, 1981.

15. Mesa redonda sobre Formación de Recursos Humanos (3a. : 1981 : México, D. F.). III Mesa redonda sobreformación de recursos humanos: maes tría. 26h. Mé xi co : Co le gio Na cio nal de Bibliotecarios, 1982. 
16. IV Mesa. Op. Cit.

17. ColegioNacionaldeBibliotecarios(México). Recomendacionessobrecapacitacióndelpersonal bibliotecarionoprofesionalylistadeactividadesprofesionalesynoprofesionales. Mé xi co : El Colegio, 1982. $16 \mathrm{~h}$.

18. IV Mesa. Op. Cit. p. 12.

19. Idem. p. 3 .

20. Ibidem.

21. II Mesa. Op. Cit.

22. IV Mesa. Op. Cit. pp. 41-45.

23. C N B. Recomendaciones. Op. Cit. Cfr.

24. Nava. Op. Cit. pp. 60-61.

25. Idem. p. 55.

26. Idem. pp. 63-66.

27. Programaparalaformacióndetécnicosanivelbachille ratoenbibliotecología. Casa Ti rao, Beatriz. México : UNAM. CCH. Departamente de Opciones Técnicas, 1988. p. III.

28. Díaz Pérez, Porfirio, OscarSa vedraHernándezy SilviaSambarino. Anteproyectodeeducación bibliotecológicaenTabasco:elcasodelniveltécnico. Sal tillo, Coah., AMBAC, 1989.p. 2.

29. Ibidem.

30. Idem. p. 3 .

31. Idem. p. 7.

32. Idem. p. 12 .

33. "Pla nes y pro gra mas de es tu dio de ba chi lle ra to y li cen cia tu ra en la ENBA". En: Bi blio te cas y Archivos. n. 3. (1977). p. 82.

ANEXOS

Cuadro 1 NIVEL DE ESTUDIOS

(117)
Cuadro 2

BACHILLERATO CON OPCION TECNICA EN BIBLIOTECONOMIA (DE $\left.117^{*}\right)$

\begin{tabular}{|l|c|c|}
\hline \multicolumn{1}{|c|}{ NIVEL } & CANT IDAD 117 & \% \\
\hline \hline Primaria únicamente & 0 & 0 \\
\hline Secundaria únicamente & 7 & 5.9 \\
\hline Bachillerato únicamente & 27 & 23 \\
\hline Licenciatura únicamente & $83^{*}$ & 70.9 \\
\hline
\end{tabular}

\begin{tabular}{|c|c|c|}
\hline CON OPCION TECNICA & CANTIDAD & $\%$ \\
\hline \hline S I & 29 & 24.7 \\
\hline NO & 81 & 69.23 \\
\hline
\end{tabular}

* En este ni vel se in clu ye ron a los es tu dian tes que es tán aún cur san do la licenciatura, en sus últimos semestres 
Cuadro 3

RAZONES POR LAS CUALES ESTUDIO LA OPCION TECNICA EN BIBLIOTECONOMIA (DE 29)

\begin{tabular}{|l|c|c|}
\hline \multicolumn{1}{|c|}{ RAZONES } & $\begin{array}{c}\text { CANTID AD } \\
\text { (29) }\end{array}$ & $\%$ \\
\hline \hline Porque era la única opción & 3 & 10.3 \\
\hline $\begin{array}{l}\text { A sujerencia del orientador voca- } \\
\text { cional }\end{array}$ & 3 & 10.3 \\
\hline $\begin{array}{l}\text { Porque me encontraba trabajan- } \\
\text { do en una biblioteca }\end{array}$ & 4 & 13.7 \\
\hline $\begin{array}{l}\text { Por influencia de familiares y } \\
\text { amigos }\end{array}$ & 4 & 13.7 \\
\hline $\begin{array}{l}\text { Por otras, intereses por adminis- } \\
\text { tración de bibliotecas }\end{array}$ & 1 & 3.4 \\
\hline Por conocer la carrera & 4 & 13.7 \\
\hline Por interés personal & 3 & 10.3 \\
\hline Por vocación de servicio & 1 & 3.4 \\
\hline Porque me gusta & 2 & 6.8 \\
\hline Por gusto a los libros & 1 & 3.4 \\
\hline No contestó & 3 & 10.3 \\
\hline
\end{tabular}

Cuadro 4

ESCUELAS EN QUE SE HA ESTUDIADO LA OPCION TECNICA EN BIBLIOTECONOMIA (DE 29)

\begin{tabular}{|l|c|c|}
\hline \multicolumn{1}{|c|}{ ESCUELA } & $\begin{array}{c}\text { CANTIDAD } \\
\text { (29) }\end{array}$ & $\%$ \\
\hline $\begin{array}{l}\text { Escuela Nacional de Biblioteco- } \\
\text { nomía y Archivonomía }\end{array}$ & 14 & 48 \\
\hline Colegio de Bachilleres & 6 & 21 \\
\hline CCH, UNAM & 7 & 24 \\
\hline Sin respuesta & 2 & 7 \\
\hline
\end{tabular}

Cuadro 5

CONSIDERA QUE INFLUYO LA OPCION TECNICA EN BIBLIOTECONOMIA PARA SU CONTRATACION (DE 29)

\begin{tabular}{|c|r|r|}
\hline CONSIDERA QUE INFLUYO & $\begin{array}{c}\text { CANTIDAD } \\
(29)\end{array}$ & $\%$ \\
\hline \hline S I & 22 & 75.8 \\
\hline NO & 5 & 17.2 \\
\hline NO CONTESTO & 2 & 6.8 \\
\hline
\end{tabular}

Cuadro 6

ESTUDIOS SUPERIORES (DE 83)

\begin{tabular}{|l|c|c|}
\hline \multicolumn{1}{|c|}{ LICENCIATURA } & $\begin{array}{c}\text { CANTIDAD } \\
(83)\end{array}$ & $\%$ \\
\hline \hline En biblioteconomia & 50 & 60.24 \\
\hline En otras áreas & 33 & 39.75 \\
\hline
\end{tabular}

\section{Cuadro 7}

RAZONES POR LAS CUALES ESTUDIO LA LICENCIATURA EN BIBLIOTECONOMIA (DE 50)

\begin{tabular}{|l|c|c|}
\hline \multicolumn{1}{|c|}{$\begin{array}{c}\text { RAZONES } \\
\text { (se contestó más de } \\
\text { una opción) }\end{array}$} & $\begin{array}{c}\text { CANTIDAD } \\
\text { (50) }\end{array}$ & $\%$ \\
\hline \hline $\begin{array}{l}\text { Porque cursé el bachillerato en } \\
\text { biblioteconomía }\end{array}$ & 9 & 18 \\
\hline $\begin{array}{l}\text { Porque me encontraba en una } \\
\text { biblioteca }\end{array}$ & 12 & 24 \\
\hline $\begin{array}{l}\text { Porque tengo familiares y ami- } \\
\text { gos que influyeron en mi deci- } \\
\text { sión }\end{array}$ & 5 & 10 \\
\hline $\begin{array}{l}\text { Otras, decisión personal } \\
\text { Porque me gusta }\end{array}$ & 2 & 42 \\
\hline $\begin{array}{l}\text { Por el mal servicio que se presta } \\
\text { en las bibliotecas }\end{array}$ & 2 & 12 \\
\hline Por orientación vocacional & 2 & 4 \\
\hline $\begin{array}{l}\text { Por medio de material bibliográfi- } \\
\text { co }\end{array}$ & 2 & 4 \\
\hline $\begin{array}{l}\text { Por perspectivas de trabajo rápi- } \\
\text { do }\end{array}$ & & 2 \\
\hline
\end{tabular}

Cuadro 8

LICENCIATURA EN BIBLIOTECONOMIA CON LA OPCION TECNICA (DE 50)

\begin{tabular}{|c|c|c|}
\hline CON OPCION & CANTIDAD & $\%$ \\
\hline \hline S I & 14 & 28 \\
\hline NO & 36 & 72 \\
\hline
\end{tabular}

\section{Cuadro 9}

RAZONES POR LAS CUALES ESTUDIO LA LICENCIATURA EN BIBLIOTECONOMIA DE LOS 14 QUE CURSARON LA OPCION TECNICA, (SE CONTESTO MAS DE UNA OPCION)

\begin{tabular}{|l|c|c|}
\hline \multicolumn{1}{|c|}{ RAZONES } & CANTIDAD & $\%$ \\
\hline \hline $\begin{array}{l}\text { Porque cursé el bachillerato téc- } \\
\text { nico en biblioteconomía }\end{array}$ & 7 & 50 \\
\hline $\begin{array}{l}\text { Porque me encontraba trabajan- } \\
\text { do en una biblioteca }\end{array}$ & 2 & 14.2 \\
\hline $\begin{array}{l}\text { Porque tengo familia y amigos } \\
\text { que influyeron en mi decisión }\end{array}$ & 1 & 7.1 \\
\hline Otras, porque me gusta & 7 & 50 \\
\hline Por ofrecer servicio & 3 & 21.4 \\
\hline
\end{tabular}

